\title{
Autoimmune polyglandular syndrome type 1 with diabetes insipidus: a case report
}

\author{
JiaQi Chen, Ting Lu, ChenXiao Liu, Yun Zhao, AiJie Huang, XingNa Hu, Min Li, Rong Xiang, Min Feng and \\ HongHong Lu*
}

\begin{abstract}
Background: Autoimmune polyendocrine syndrome type 1 (APS-1) is a rare monogenic inherited disease caused by mutations of the autoimmune regulator gene (AIRE). The three major components of this syndrome are chronic mucocutaneous candidiasis, hypoparathyroidism and adrenocortical insufficiency.

Case presentation: We report a 20-year-old male who was clinically diagnosed with APS-1 at the age of 15. He was admitted to our department this time for suffering from polyuria and polydipsia for 6 months and was finally diagnosed with diabetes insipidus. Whole-exome sequencing (WES) revealed a novel compound heterozygous mutation of the AIRE gene - the c.239 T > G (p.Val80Gly) variant on one allele and the copy number variant (CNV) of $21 \mathrm{q} 22.3(\mathrm{chr} 21: 45,670,150-45,706,528)^{*} 1$ on the other.
\end{abstract}

Conclusions: This case suggests that diabetes insipidus is a rare component of APS-1 and expands the variety of mutations on AIRE gene.

Keywords: Autoimmune polyendocrine syndrome type 1, Diabetes insipidus, Autoimmune regulator gene

\section{Background}

Autoimmune polyendocrine syndrome type 1 (APS-1) is a rare monogenic inherited disease caused by mutations of the autoimmune regulator gene (AIRE) located on chromosome 21q22.3 [1]. The prevalence of APS-1 is quite low and varies in different populations. It is relatively higher in Iranian Jews (1:9000), Sardinians (1: 14,400), and Finns (1:25,000) [2-4]. However, APS-1 is quite rare in Eastern Asians [5, 6].

The classical triad of this syndrome is chronic mucocutaneous candidiasis, hypoparathyroidism, and adrenal insufficiency. The clinical diagnosis is based on the presence of at least two of the three symptoms. As AIRE has a crucial role in promoting self-tolerance in the thymus, APS-1 patients may also present other autoimmune disorders such as autoimmune thyroiditis, type 1 diabetes,

\footnotetext{
* Correspondence: luhongh@163.com

Department of Endocrinology and Metabolism, The Affiliated Suzhou Hospital of Nanjing Medical University, Suzhou Municipal Hospital, Suzhou, Jiangsu, China
}

hypertrophic hypogonadism, and pernicious anemia [7]. As the clinical manifestations varies, the genetic and immunological features are also important in the diagnosis of this syndrome [8]. In this manuscript, we reported a Chinese APS-1 patient with a rare component- central diabetes insipidus. The genetic analysis revealed a novel compound heterozygous mutation.

\section{Case presentation}

A 20-year-old Chinese male was admitted to our department due to the complaint of polyuria and polydipsia for six months. The patient was born of non-consanguineous parents and was clinically diagnosed with APS-1 5 years ago. The patient suffered from chronic mucocutaneous candidiasis since the age of 9 years. Both his nails and oral cavity were affected. Later on he developed adrenal insufficiency and autoimmune thyroiditis at the age 15 years. Alopecia was also presented when he was 15 years old. The patient was then clinically diagnosed as APS- 1 by us and visited our department once a year for regular follow-

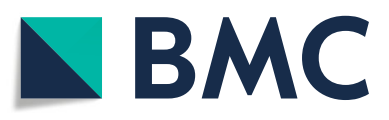

(c) The Author(s). 2021 Open Access This article is licensed under a Creative Commons Attribution 4.0 International License, which permits use, sharing, adaptation, distribution and reproduction in any medium or format, as long as you give appropriate credit to the original author(s) and the source, provide a link to the Creative Commons licence, and indicate if changes were made. The images or other third party material in this article are included in the article's Creative Commons licence, unless indicated otherwise in a credit line to the material. If material is not included in the article's Creative Commons licence and your intended use is not permitted by statutory regulation or exceeds the permitted use, you will need to obtain permission directly from the copyright holder. To view a copy of this licence, visit http://creativecommons.org/licenses/by/4.0/. The Creative Commons Public Domain Dedication waiver (http://creativecommons.org/publicdomain/zero/1.0/) applies to the data made available in this article, unless otherwise stated in a credit line to the data. 
ups. The adrenal and thyroid function were evaluated every follow-up and the dose of hydrocortisone and levothyroxine were adjusted accordingly. The serum calcium level and PTH level were also screened every year and no abnormal results were found. There were no other important complaints in the 5-year-follow-up until he was 20 years old. The symptoms and managements are summarized in Table 1.

As being a common component of APS-1, type 1 diabetes was our first consideration. However, oral glucose tolerance test revealed that fasting and 2-h glucose levels were $4.25 \mathrm{mmol} / \mathrm{L}$ and $4.39 \mathrm{mmol} / \mathrm{L}$, respectively. The HbA1c level was $4.96 \%$. Thus, diabetes mellitus was excluded. Meanwhile, adrenal function, thyroid function, and parathyroid function were reevaluated. All the results were within normal range. Interestingly, the $24 \mathrm{~h}$ urine output of the patient was $9.1 \mathrm{~L}$. And the patient's urine test revealed that urine specific gravity was 1.004 and osmolality was $114 \mathrm{mOsm} / \mathrm{kg} \mathrm{H} 2 \mathrm{O}$. Impression of diabetes insipidus was highly suspected and water deprivation test and vasopressin administration was then performed. The result (Fig. 1) suggested that our patient suffered from central diabetes insipidus. Urine osmolality was elevated from $114 \mathrm{mOsm} / \mathrm{kg} \quad \mathrm{H} 2 \mathrm{O}$ to $368 \mathrm{mOsm} / \mathrm{kg} \mathrm{H} 2 \mathrm{O}$ during water deprivation and was further increased to $566 \mathrm{mOsm} / \mathrm{kg} \mathrm{H} 2 \mathrm{O}$ after vasopressin administration. And plasma osmolality before water deprivation test and before and after vasopressin administration were 300,313 , and $314 \mathrm{mOsm} / \mathrm{kg} \mathrm{H} 2 \mathrm{O}$, respectively. A further MRI was performed and there were no significant findings in pituitary and hypothalamus. Nor were tumors observed in MRI imaging. Desmopressin of $0.1 \mathrm{mg}$ every $8 \mathrm{~h}$ was then prescribed to the patient and the symptoms improved. Urine output was approximately $3 \mathrm{~L}$ per day when the patient was discharged.

Furthermore, Whole-exome sequencing (WES) was performed this time. WES revealed a compound heterozygous mutation of the AIRE gene - the c.239 T > G (p.Val80Gly) variant on one allele and the copy number variant (CNV) of 21q22.3(chr21:45,670,150-45,706,528)*1 on the other. Both patient's parents were examined for this mutation. The patient's mother carries the same heterozygotes variant of c.239 T > G (p.Val80Gly), while the father is a wildtype (Fig. 2).

\section{Discussion and conclusion}

In our case, we described a new novel compound heterozygous mutation of the AIRE gene in this patient clinically diagnosed as APS-1. The c.239 T> G (p.Val80Gly) variant was previously reported [9], while the CNV of $21 \mathrm{q} 22.3$ (chr21:45,670,150-45,706,528)*1 is newly discovered.

As mentioned above, AIRE promotes the expression of tissue specific antigens in medullary thymic epithelial cells for negative selection of autoreactive $\mathrm{T}$ effector cells [7]. Up to date, more than 100 mutations have been reported in AIRE, varying from single nucleotide variant to large deletions across exons. Most mutations are autosomal-recessively inherited. As some certain populations have higher prevalence of this disease, several mutations are more common among these populations [10, 11]. The p.Y85C is more common in Iranian Jewish APS-1 patients. The p.R139X mutation is the most common in Sardinia patients and seems to be related with a more severe clinical phenotype. The p.R257X is a typical mutation in Finnish and Russian patients. The c.967979del13bp mutation is also common in different populations.

AIRE consists of four major functional domains: the CARD domain, the SAND domain, and two PHD domains. The CARD domain is transcripted and translated from exon 1 and 2, which was affected in our case. The CARD domain is involved in the process of AIRE homomultimerization, which is essential to perform its function [12, 13]. It was believed that AIRE formed dimerization or tetramerization to play its function. However, a recent research found that it was vital for its function that AIRE CARD domain forms filaments and large assembly rather than the formation of dimerization or tetramerizaiton [14]. And furthermore, this assembly mediates foci formation and transcriptional activity of AIRE [14].

Table 1 The presentations of the patient

\begin{tabular}{llll}
\hline Components & $\begin{array}{l}\text { Age of } \\
\text { diagnosis }\end{array}$ & Presentation & Treatment \\
\hline $\begin{array}{l}\text { Chronic mucocutaneous } \\
\text { candidiasis }\end{array}$ & 9 & Oral cavity and nails candidiasis & Course of antifungal drugs \\
Adrenal insufficiency & 15 & Hyperpigmentation, weakness and fatigue & $\begin{array}{l}\text { Maintenance therapy } \\
\text { (hydrocortisone) } \\
\text { Autoimmune thyroiditis }\end{array}$ \\
$\begin{array}{ll}\text { Alopecia } \\
\text { Diabetes insipidus }\end{array}$ & 15 & $\begin{array}{l}\text { Subclinical hypothyroidism and high titers of } \\
\text { antibodies }\end{array}$ & No treatment \\
\hline
\end{tabular}




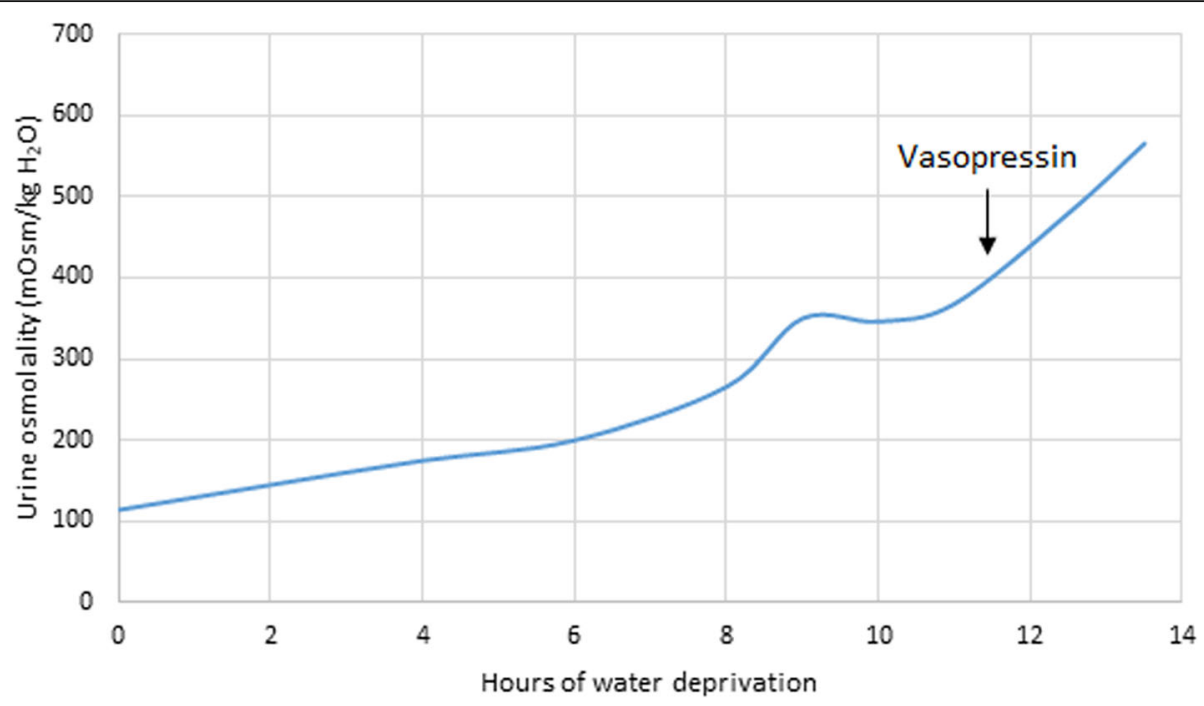

Fig. 1 Urine osmolality during a dehydration test. Vasopressin was administrated $11.5 \mathrm{~h}$ after water deprivation

In our case, both of the two variants locate on CARD domain. The variant of c.239 T > G(p.Val80Gly) was previously reported in two Indian patients [9]. This mutation was believed to be pathogenic while it is homozygous. Both of the two patients had this homozygous mutation. One of the patients was the product of a consanguineous marriage. As for the other patient, both her parents carried a heterozygotes variant. And she had an unaffected brother. In our case, the mother of our patient who also carried this heterozygotes variant was not affected. The CNV of 21q22.3(chr21:45,670,15045,706,528)*1 including AIRE exon 1 and 2 makes one

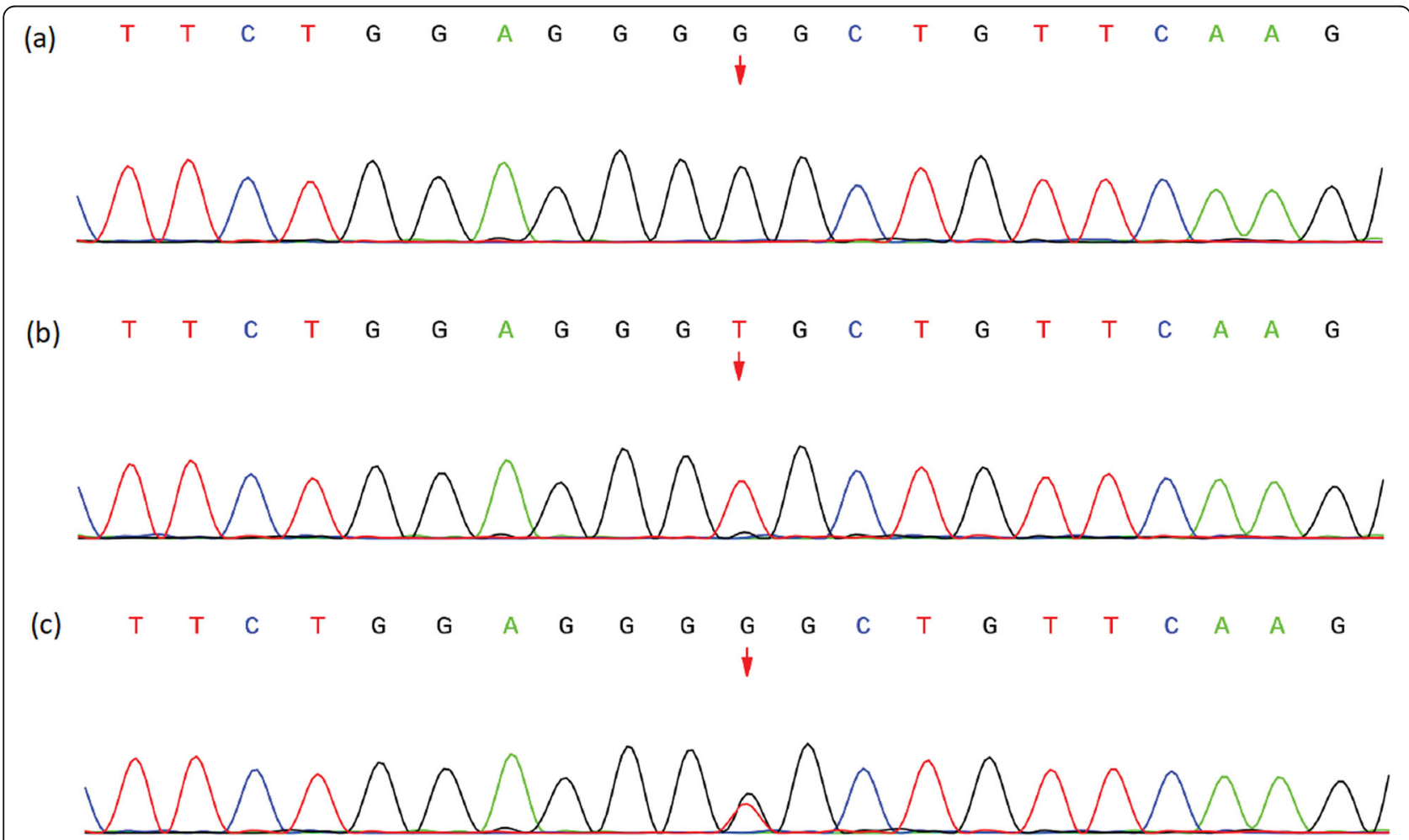

Fig. 2 Sanger sequencing chromatogram of AIRE gene. a The patient carries the variant of c.239 T>G (p.Val80Gly). b The patient's father is a wildtype. c The patient's mother carries the same heterozygotes variant 
allele of AIRE short of CARD domain. Both of our patient's parents were not found to carry this CNV. We think the CNV itself may affect the function of AIRE as a transcriptional regulator. However, we believe that, in our case, the CNV makes the c.239 $\mathrm{T}>\mathrm{G}$ (which locates on AIRE exon 2) variant on the other allele to some extent "homozygous", and the compound heterozygous mutation led to the development of APS-1.

Although APS-1 is a monogenic disease, there is no strong correlation between genotype and clinical phenotype. A wide spectrum of clinical manifestations have been reported in APS-1 cases. And clinical expressions may differ even in siblings carrying the same genetic variant. However, some researchers proposed a clinical classification of APS-1, which to some extent, associates with genetic variant types: the "classical" and "non-classical" APS-1 [15]. The "classical" APS-1 is characterized by the presence of at least two of three main components and autoimmune antibodies, and is homozygous or compound heterozygous recessive inherited. The "non-classical" APS-1 varies in clinical phenotype from the main components of APS-1 to isolated organspecific autoimmunity and is usually inherited in a heterozygous dominant manner. Our patient suffered from chronic mucocutaneous candidiasis and adrenal insufficiency. These two clinical features makes the clinical diagnosis of APS-1. Together with the compound heterozygous mutation, our patient met the criteria of "classical" APS-1.

Reported by previous studies $[2,4,16-18]$, chronic mucocutaneous candidiasis is the most common and usually the first component of APS-1, and it usually occurs before the age of 5 . Hypoparathyroidism is the most common endocrine component and usually appears after chronic mucocutaneous candidiasis. Adrenal insufficiency is less common than hypoparathyroidism and has an incidence peak at the age of 12 years. The most three frequent minor manifestations are autoimmune thyroiditis, type 1 diabetes, and autoimmune hepatitis. Our patient developed chronic mucocutaneous candidiasis at the age of 9 years and then developed adrenal insufficiency and autoimmune thyroiditis at the age 15 years. $\mathrm{He}$ also presented alopecia, which is also a common minor components of APS-1 reported in a Russian cohort with 112 APS-1 patients [11].

Interestingly, our patient was referred to us for his polyuria and polydipsia. Water deprivation test and vasopressin administration revealed that our patient suffered from central diabetes insipidus. Further pituitary MRI found no significant lesions. The causes of central diabetes insipidus are usually pituitary lesions, including trauma, tumor, or infection. Lymphocytic filtration is now recognized also a common cause of central diabetes insipidus. And it may recover to normal while diabetes insipidus is left permanent. There are only few cases of diabetes insipidus caused by APS. In a study [19] including 79 children and young adults with central diabetes insipidus, only in one patient diabetes insipidus was caused by APS. And the patient developed polyuria and polydipsia until age 24.8 while he had been diagnosed with APS at the age of 2 years. The long period of time elapsed since APS was diagnosed to the presentation of diabetes insipidus is also seen in our patient. Another cohort [20] from Turkey including 34 children with central diabetes insipidus revealed that only in one case diabetes insipidus was caused by APS. The development of central diabetes insipidus in APS patients may be due to autoimmune process. In a large cohort of 2385 APS patients, 22 of them with central diabetes insipidus, and most of them developed diabetes insipidus after the age of 20 years, was selected out for screening for antibodies to AVP-secreting cells (AVPcAb). AVPcAb was positive in 15 of the 22 patients and consisted positive during the 5-year follow-up. While in the control group of 13 idiopathic central diabetes insipidus, only 5 of them were $A V P c A b$ positive [21]. The presence of AVPcAb suggested that due to the autoimmune pathogenesis, diabetes insipidus is also a component in APS. The damage of AVP cells may be chronic, which may be associated with the late development of central diabetes insipidus in APS patients.

Through this case, we reported a novel compound heterozygous mutation of AIRE in an APS- 1 patient. More importantly, we discussed the clinical components of APS-1 and learned that central diabetes insipidus may also be an important component of APS-1. For patients, especially children and young adults, with "idiopathic" central diabetes insipidus and other endocrine deficiencies, APS-1 must be considered. Genetic analysis and AVPcAb should be performed if the tests are available.

\section{Abbreviations \\ AIRE: Autoimmune Regulator gene; APS-1: Autoimmune Polyglandular Syndrome type 1; AVPCAb: Antibodies to AVP-secreting cells; CNV: Copy number variant; WES: Whole-exome sequencing}

\section{Acknowledgements}

We appreciate the patient and his family's cooperation in this case report. We thank Rampersad Sharvan for his linguistic assistance during the preparation of this manuscript.

\section{Authors' contributions}

JQC and HHL designed the study. TL, YZ, and XNH provided medical care to the patient. $A J H, M L$, and $R X$ performed the genetic analysis. JQC wrote the manuscript. CXL collaborated in the analysis of the case and writing of the manuscript. MF and HHL supervised the management of the case. All authors read and approved the final manuscript.

Funding

No funding was received. 


\section{Availability of data and materials}

All data related to this report are stored at Nanjing Medical University affiliated Suzhou Hospital (Jiangsu Province, China), and are available from the corresponding author on reasonable request.

\section{Declarations}

Ethics approval and consent to participate

All procedures performed in the research involving human participants were in accordance with the Helsinki declaration. Informed consent was obtained from all individual participants included in the study.

\section{Consent for publication}

An informed written consent was obtained from the patient and his parents for the publication of this case report.

\section{Competing interests}

All authors declare no competing interests.

Received: 30 March 2021 Accepted: 20 July 2021

Published online: 03 August 2021

\section{References}

1. Finnish-German APECED consortium. An autoimmune disease, APECED, caused by mutations in a novel gene featuring two PHD-type zinc-finger domains. Nat Genet. 1997;17(4):399-403.

2. Zlotogora J, Shapiro MS. Polyglandular autoimmune syndrome type I among Iranian Jews. J Med Genet. 1992;29(11):824-6.

3. Rosatelli MC, Meloni A, Meloni A, Devoto M, Cao A, Scott HS, Peterson P, Heino M, Krohn KJ, Nagamine K, et al. A common mutation in Sardinian autoimmune polyendocrinopathy-candidiasis-ectodermal dystrophy patients. Hum Genet. 1998;103(4):428-34.

4. Ahonen P, Myllarniemi S, Sipila I, Perheentupa J. Clinical variation of autoimmune polyendocrinopathy-candidiasis-ectodermal dystrophy (APEC ED) in a series of 68 patients. N Engl J Med. 1990;322(26):1829-36.

5. Sato K, Nakajima K, Imamura H, Deguchi T, Horinouchi S, Yamazaki K, Yamada E, Kanaji Y, Takano K. A novel missense mutation of AlRE gene in a patient with autoimmune polyendocrinopathy, candidiasis and ectodermal dystrophy (APECED), accompanied with progressive muscular atrophy: case report and review of the literature in Japan. Endocr J. 2002;49(6):625-33.

6. Yan Z, Gang X, Xie X, Gao Y, Li Z, Wang G. A case report and literature review. Medicine. 2020;99(18):e20000.

7. Anderson MS, SU MA. AIRE expands: new roles in immune tolerance and beyond. Nat Rev Immunol. 2016;16(4):247-58.

8. Husebye ES, Perheentupa J, Rautemaa R, Kampe O. Clinical manifestations and management of patients with autoimmune polyendocrine syndrome type I. J Intern Med. 2009:265(5):514-29.

9. Zaidi G, Sahu RP, Zhang L, George G, Bhavani N, Shah N, Bhatia V, Bhansali A, Jevalikar G, Jayakumar RV, et al. Two novel AIRE mutations in autoimmune polyendocrinopathy-candidiasis-ectodermal dystrophy (APEC ED) among Indians. Clin Genet. 2009;76(5):441-8.

10. Pitkanen J, Peterson P. Autoimmune regulator: from loss of function to autoimmunity. Genes Immun. 2003;4(1):12-21.

11. Orlova EM, Sozaeva LS, Kareva MA, Oftedal BE, Wolff ASB, Breivik L, Zakharova EY, Ivanova ON, Kämpe O, Dedov II, et al. Expanding the phenotypic and genotypic landscape of autoimmune polyendocrine syndrome type 1. J Clin Endocrinol Metab. 2017;102(9):3546-56.

12. Maslovskaja J, Saare M, Liiv I, Rebane A, Peterson P. Extended HSR/CARD domain mediates AIRE binding to DNA. Biochem Biophys Res Commun. 2015;468(4):913-20.

13. Perniola R, Musco G. The biophysical and biochemical properties of the autoimmune regulator (AIRE) protein. Biochim Biophys Acta. 2014;1842(2): 326-37.

14. Huoh Y, Wu B, Park S, Yang D, Bansal K, Greenwald E, Wong WP, Mathis D, Hur S. Dual functions of Aire CARD multimerization in the transcriptional regulation of T cell tolerance. Nat Commun. 2020;11(1):1625.

15. Oftedal BE, Hellesen A, Erichsen MM, Bratland E, Vardi A, Perheentupa J, Kemp EH, Fiskerstrand T, Viken MK, Weetman AP, et al. Dominant mutations in the autoimmune regulator AIRE are associated with common organspecific autoimmune diseases. Immunity. 2015;42(6):1185-96.
16. Wolff AS, Erichsen MM, Meager A, Magitta NF, Myhre AG, Bollerslev J, Fougner KJ, Lima K, Knappskog PM, Husebye ES. Autoimmune polyendocrine syndrome type 1 in Norway: phenotypic variation, autoantibodies, and novel mutations in the autoimmune regulator gene. J Clin Endocrinol Metab. 2007;92(2):595-603.

17. Orlova EM, Bukina AM, Kuznetsova ES, Kareva MA, Zakharova EU, Peterkova VA, Dedov II. Autoimmune polyglandular syndrome type 1 in Russian patients: clinical variants and autoimmune regulator mutations. Horm Res Paediatr. 2010;73(6):449-57.

18. Proust-Lemoine E, Saugier-Veber P, Lefranc D, Dubucquoi S, Ryndak A, Buob D, Lalau JD, Desailloud R, Weill J, Prin L, et al. Autoimmune polyendocrine syndrome type 1 in north-western France: AIRE gene mutation specificities and severe forms needing immunosuppressive therapies. Horm Res Paediatr. 2010;74(4):275-84

19. Maghnie M, Cosi G, Genovese E, Manca-Bitti ML, Cohen A, Zecca S, Tinelli C, Gallucci M, Bernasconi S, Boscherini B, et al. Central diabetes insipidus in children and young adults. N Engl J Med. 2000;343(14):998-1007.

20 Catli G, Abaci A, Demir K, Ulusoy E, Altincik A, Buyukgebiz A, Bober E. Clinical profile and etiologies of children with central diabetes insipidus: a single-center experience from Turkey. J Pediatr Endocrinol Metab. 2012; 25(5-6):499-502.

21. De Bellis A, Colao A, Bizzarro A, Di Salle F, Coronella C, Solimeno S, Vetrano A, Pivonello R, Pisano G, Lombardi G, et al. Longitudinal study of vasopressin-cell antibodies and of hypothalamic-pituitary region on magnetic resonance imaging in patients with autoimmune and idiopathic complete central diabetes insipidus. J Clin Endocrinol Metab. 2002;87(8): $3825-9$.

\section{Publisher's Note}

Springer Nature remains neutral with regard to jurisdictional claims in published maps and institutional affiliations.

\section{Ready to submit your research? Choose BMC and benefit from:}

- fast, convenient online submission

- thorough peer review by experienced researchers in your field

- rapid publication on acceptance

- support for research data, including large and complex data types

- gold Open Access which fosters wider collaboration and increased citations

- maximum visibility for your research: over $100 \mathrm{M}$ website views per year

At BMC, research is always in progress.

Learn more biomedcentral.com/submissions 